\title{
University Strategy, Accreditation Standards, and the Applied Education Mission: Using the Student Consulting to Build Bridges
}

\author{
Whitney O. Peake ${ }^{1}$, Paula W. Potter ${ }^{1}$ \\ 1 Western Kentucky University \\ Keywords: Strategy, Accreditation, Mission, Consulting, Student \\ https://doi.org/10.53703/001c.32465
}

\section{Small Business Institute Journal}

Vol. 18, Issue 1, 2022

\begin{abstract}
As a high impact practice and well-established pedagogical tool, student consulting projects are a means to bridge the needs of multiple stakeholders. The purpose of this research is to provide discussion around and illustration of how university strategy, applied education mission and accreditation standards can integrate under the umbrella of student consulting projects. While these are obviously not the sole means to address engagement and impact, student consulting projects provide an effective means to innovate and engage students within and outside the classroom, and to yield measurable, sustainable impact for the community. To do so, we explore how through these structures, universities can curate currency and leverage future opportunities.
\end{abstract}

\section{Introduction}

"Establish WKU as a regional lighthouse to provide resources, attract talent, and nurture intellectual capital in the communities we serve."

- Western Kentucky University Strategic Plan

"The school demonstrates positive societal impact through internal and external initiatives and/or activities, consistent with the school's mission, strategies, and expected outcomes."

- AACSB Standard 9: Engagement and Societal Impact

"The mission of the Gordon Ford College of Business is
actively support and engage students, faculty, staff, and
community in academic and lifelong professional develop-
ment, providing the foundation needed to lead in today's
diverse business environments."
- Mission of the Gordon Ford College of Business, WKU

The strategic plan item from WKU and mission for the Gordon Ford College of Business referenced above are not distinctly different than those of many other regional comprehensive universities across the United States. Regional comprehensives generally strive to serve our communities and the businesses and stakeholders that make up those communities, and we work to provide our students with concrete, transferable skills to meet the needs of the businesses in our own communities and beyond. We engage in the community for the win-win, to provide resources to local businesses and to secure experiences for our students in working with real businesses through applied projects. With Standard 9 published by AACSB now emphasizing measures of engagement and societal impact for accredited colleges of business globally, we have a third, critical call to engage our students in creating positive societal impact. Via Standard 9, AACSB accredited colleges of business are now measured and judged on our performance in addressing this strategic initiative and advancing our mission. While there are myriad ways to address the call to be a regional lighthouse, create societal impact, and foster an applied education mission, student consulting projects are a means to address all three, showcasing well-defined, measurable impact in the classroom and community.

Student consulting projects are a component of experiential learning and are widely employed in business education models across the United States (Canziani \& Tullar, 2017). Generally, student consulting projects are clientbased and engage students in working with a business to conduct a feasibility analysis, create or evaluate a business model or plan, or research the market to determine opportunities for the business across functional areas (Canziani \& Tullar, 2017). Such work has been shown to support the community and develop alumni relationships (Madison \& Chawla, 1998); thus, further advancing the mission of many regional comprehensive universities. While student-led consulting projects can take on a variety of forms at any level in the curriculum, students learn to apply theory to practice and think critically, which are key success factors for any undergraduate experience (Cook \& Belliveau, 2006; Canziani \& Tullar, 2017). With these broad parameters, student consulting projects provide resources to the business community, demonstrate positive societal impact with tangible outcomes, and build a foundation for students to enter and lead in both large and small business contexts.

While student consulting projects provide a clear means to address regional strategies, applied education missions, and accreditation standards, they are also a component of High Impact Practices (HIPS) (Kuh, 2008), and facilitate a mechanism through which collaborative, multidisciplinary curricula can move forward on college campuses. Student consulting projects, as a high impact practice, are inclusive community builders for students and have been shown through research to improve retention (Conefrey, 2018), particularly for vulnerable student groups, such as firstgeneration students. Such projects help students develop 
skills that can shape their growth as responsible community members, who better understand the role of small businesses within communities. These experiences help students put human faces and real-world constraints with small business names to more fully understand the decision-making frameworks and obstacles that business owners face.

The purpose of this research is to provide discussion around and illustration of how university strategy, applied education mission and accreditation standards can integrate under the umbrella of student consulting projects. While these are obviously not the sole means to address engagement and impact, student consulting projects provide an effective means to innovate and engage students within and outside the classroom, and to yield measurable, sustainable impact for the community. To do so, we explore how through these structures, universities can curate currency and leverage future opportunities. In the following section we provide the history and structure of these programs in our own institution to lend context. Then, we provide key points for curating currency, addressing student demand, examining return on investment for such projects, creating and measuring impact, and using such activities for positive promotion for the university and community simultaneously. Finally, we build on these sections to provide some key insights to opportunities that exist through student consulting projects moving forward, and how programs and universities can enhance their value proposition to multiple stakeholders utilizing these models.

\section{Student Consulting Project History and Structure at WKU}

As a high-impact practice (Kuh, 2008), student consulting projects through the Small Business Institute ${ }^{\circledR}$ at Western Kentucky University have traditionally culminated in a capstone project experience. Each spring, a relatively small number of graduating seniors from across the Gordon Ford College of Business enroll in the entrepreneurship capstone in lieu of the traditional case-method strategy capstone alternative. Although the student consulting experience began in the early 2000's at WKU, some variability in delivery had occurred over time with faculty turnover. Within the past 6 years, this course has focused on 4-6 community, small business clients with typically 20-30 students enrolled. From spring 2015 to spring 2020, these consulting projects addressed the needs of 28 clients, involving 142 students in more than 7,800 consulting hours. Students engaged in these projects through the alternative capstone format, won 5 national Project of the Year student consulting project awards through the $\mathrm{SBI}^{\circledR}$.

Although published research confirms the value of student-led consulting projects, we have likewise examined their impact on recent graduates. In 2019, the Gordon Ford College of Business surveyed recent alumni who had graduated between 2012 and 2018. This survey yielded 116 total responses. All students in the college of business at WKU take courses in a business core curriculum. This survey examined the effectiveness of this core curriculum in preparing students for career success and relevance in their dayto-day roles. The results indicated that the student consulting capstone course we offer, was rated on average a $4.84 / 5.00$ in terms of relevance to recent alumni career success. This was the highest rating of any course in the college of business core curriculum. The traditional case study strategy capstone, in comparison, was rated at 3.84/5.00. Further, when asked how often students use the topics from these core classes, where $1=$ never and $5=$ every day, recent graduates, on average, rated the student consulting skills and knowledge at 4.32/5.00. This was the second highest rating of any core course, only behind the course which covers basic computer and Microsoft Office literacy. The takeaway here is that student consulting projects provide students with relevant skills used in their day-to-day work life, and that they recognize the value derived from these experiences.

As is the case for many universities, the 2020-2021 academic year has been an untraditional one at WKU. Due to staffing shortages the consulting capstone course was placed on hold for spring 2021. Resource shortages, however, often breed creativity. Given the importance of applied learning and experiences to Generation $\mathrm{Z}$, and the call of the university to engage students in the community, we created an additional student consulting experience structure. The basic entrepreneurship course at WKU, ENT 312 is a general education (Colonnade) course. Students from across the university can enroll in this course to fulfill the systems thinking requirement for general education, and oftentimes the make-up of sections for these courses are $30-50 \%$ nonbusiness majors. While this is not a capstone experience, incorporating smaller-scale consulting projects into this course creates an opportunity for students to engage in collaborative projects and community-based learning - both critical elements of HIPS (Kuh, 2008). Although smaller-scale, students are working with live clients in the community to solve real business problems with valueadded solutions. The response from both students and clients thus far has been overwhelmingly positive.

Two sections of this course have partnered with a local nonprofit, the People's Opportunity Program for Underserved Populations to assist five clients with their businesses. POP-UP is a program housed under the local Housing Authority's nonprofit arm, and is designed to provide low interest loans to low income and minority entrepreneurs. Such collaborations allow students to see directly how their value-added solutions can help resource constrained start-ups grow in key areas. By mid-terms in spring 2021, students had helped with multiple issues including social media plans and mock-ups, website redesigns, and logo and marketing materials designs for their clients. While these are not capstone level projects, they will continue to be an integral part of this course into the future, particularly given the research that exists on the importance of student consulting projects as a key learning, retention, and career preparation tool. Further, the written and oral communication components of these projects allow for critical pieces of assurance of learning for SACSCOC or AACSB accreditation. 


\section{Student Consulting Projects Create Measurable Impacts for Missions and Goals}

Every strategic objective, mission, and standard must have measurable impacts. Student-led consulting projects can provide a very effective means to do so. While the benefit to students and the community through these projects are undeniable and meaningful, faculty and administrators also take on these projects with enlightened self-interest. For these student consulting projects to yield benefit beyond student learning and the single community business that was central to the student consulting project, they must be strategically tracked, measured, and publicized. But, questions then arise as to how to do this most effectively.

The answer to this question is generally, "it depends." However, as faculty and administrators, it is critical to determine what metrics are needed. Perhaps it is the number of students engaged in such projects, the number of clients, student time spent engaged in the community, student time spent on strategic recommendations, time community businesses spend on campus, etc. To ensure the greatest accuracy in reporting, professors who have long conducted student consulting projects have a time log for students to complete as a weekly check-in. This is a best practice for ensuring more accurate record keeping related to class time, team meetings, project work, client meetings, etc. This also allows for an impactful summary across the course for the amount of time students spent engaged in their community and provides a helpful comparison of teams' effort levels. For an example spreadsheet that can easily be reproduced for teams in Google Sheets, please see Appendix 1.

To further enhance legitimacy, universities can also enter student consulting projects into competitions, such as the Small Business Institute ${ }^{\circledR}$ Project of the Year competition. Winning awards lends credibility to the caliber of work being conducted, since schools in these competitions are benchmarked against one another in national competition. Further, competitions like the SBI Project of the Year competition typically allow winning teams to present their projects, which engages students in student research-type experiences, yet another high impact practice.

Student consulting projects have undeniable benefits to students, clients, and faculty and administrators. They provide means to engage with the community in "town and gown" type efforts, and make students more employable, yielding enhanced return on investment for their degree. While these arguments are straightforward and supported by research, administrators are accountable for reporting on this engagement and tying it to strategic priorities. At WKU, the hours logged with the community have been reported in SACSCOC accreditation reports, AACSB reviews, and to the University President as a metric for the strategic plan. Local news agencies often find these sorts of projects of value for interest pieces, with measurable impact for local business success. Engagement in these projects is a memorable "story' that admissions counselors can share with guidance counselors and parents. Students win, the community wins, faculty win, and the college and university win. Research and practice support the value of student consulting projects. The challenge is keeping them current, as student and client needs change, to continuously meet strategic objectives, missions and calls for engagement. In the subsequent section, we highlight how to curate currency with these projects across stakeholder groups.

\section{Curating Currency with Student Consulting Projects}

\section{Generational Currency}

According to a number of recent surveys, Generation $\mathrm{Z}$ (Gen Z), born after 1996, currently matriculating through universities, possesses some unique characteristics from their Millennial generation predecessors (Parker \& Igielnik, 2020). Gen $Z$ prefers hands-on projects and problems and wants to conduct analyses to apply information during class time (Nicolas, 2020). As employees, late Millennials and early Gen $\mathrm{Z}$ graduates rate their soft skills as significantly better than employers rated them on a number of factors (Cengage, 2019), including working with others in teams, ethical judgment and decision-making, written communication, critical thinking, analyzing complex problems, and applying knowledge (Hart Research Associates, 2015). The gap between employers and employees on these measures was substantive. Further, more than $85 \%$ of employers surveyed believed it was critical for universities and colleges to provide students with the skills and knowledge to complete an applied learning project, and almost $75 \%$ of respondents indicated such a project would improve career preparation (Hart Research Associates, 2015). In another recent survey, $60 \%$ of employers indicated that critical thinking skills are lacking among recent college graduates (Payscale, 2016).

With regards to learning preferences, Nicolas (2020) reports that Gen Z students prefer exact direction on assignments and have little desire for creative assignments. Given the learning preferences of these students and the problems noted in the workplace, student consulting projects can help to fill a critical skills void moving forward. In a survey of more than 2000 Gen Z workers, respondents indicated preference for self-directed learning approaches, and research by Seemiller and Grace (2016) suggests that socially conscious, engaged curriculum allows Gen Z to see learning tied to tangible change. Student consulting projects facilitate both self-directed learning and socially engaged curricular approaches to learning, which puts them squarely aligned with both employer needs and student preferences.

Studies also indicate that Gen Z students are more vulnerable and less optimistic than their predecessors and that as many as one in three report dealing with mental health issues. As such, fostering feelings of self-efficacy and a having a sense of belonging are critical to Gen Z for maintaining motivation and persisting in college. Adding to the mix is recent research (Gillen-O'Neel, 2021) which confirms that a sense of belonging is the highest contributing effect to student engagement for the Gen $\mathrm{Z}$. The same study found that factors such as low student-to-faculty ratios might mitigate the absence of a wider social support group. Further, research demonstrates a faculty member may serve as a "special person" (Ma \& Shea, 2021) in the social support group that contributes to the student's ability to overcome the challenges of adjusting to college life. Student consulting projects yield self-efficacy and provide a team atmos- 
phere for work, which cultivates belonging. Faculty engaged in student consulting project courses often create a greater bond with students, given the mentor/mentee relationship these courses require. As such, student consulting projects not only check boxes on academic preparation, they can also fill needs for social support.

\section{Currency in Showcasing Value of University Educational Experiences}

Recently the conversation among students, parents, university administrators and policymakers about the increasing cost of a college degree has escalated. More often the decision about whether a student should enroll in college, and more importantly, should a student or family make the expenditure, has centered on estimating the return on the investment (ROI). However, the attempt to determine such a return is fraught with difficulties since the calculation contains more than mere numbers or even hard data for that matter. Inputs such as the cost of tuition, books and lodging are more straightforward than outcomes such as employability and personal growth of the student. A new framework for examining degree ROI (Blagg \& Blom, 2018) focuses on minimizing risk for students not only during their enrollment stage but also throughout their college career. There are five key decision points that influence ROI: 1 . College application, 2. College selection, 3. Program selection, 4. Continued enrollment and 5. Employment. While it is understandable from an economic perspective that estimating a true return is elusive, it is exacerbated for low income or first-generation students, as they tend to over or underestimate the value of education. Of particular interest to this work is the program selection decision point. For instance, how can a program of study, and more specifically class assignments, contribute to a higher payoff to the student? In turn, the ability of the program to better prepare the student to secure employment and long-term career success ultimately has a ripple effect in the overall social economic fabric. A direct benefit (Blagg \& Blom, 2018) of increased earnings due to a college education leads to increased tax revenues. Policymakers weighing decisions on how and where best to invest monies in postsecondary institutions may well be influenced by programs demonstrating the ability to deliver job and career success. Moreover, university administrators therefore are likely to attend to and garner investment in such programs because of the ultimate two-fold dividend to students and the institution.

Students entering college now arrive not only with expectations about basic amenities like campus-wide internet connectivity; they also want the benefits of advanced learning opportunities (Arnold, 2018). In a way, their expectations are creating demand for new educational and community-building frameworks that institutions of higher education must quickly adapt to in order to attract and retain the $\mathrm{Z}$ generation as well as first generation students. One of the ways that universities can meet the expectation of advanced learning opportunities is to focus on classes and activities that develop the leadership capabilities and skills of their future graduates. Students who learn and begin to master leadership skills are more effective and thus more successful in the workplace. Roos (2014) contends that the best way to prepare students for employment is to give them direct exposure to the real problems that companies face, as well as allow students to be actively involved in the resolution of those problems. Student led consulting projects are an advanced learning opportunity that allows leadership development and problem-solving. Moreover, Garrett (2016) emphasizes that experiential learning outside the classroom, which emphasizes innovation and entrepreneurship, is the learning model of the future.

In the current environment, university administrators already have their hands full with managing budgetary concerns, faculty issues, accreditation, and student enrollment in the midst of an ever- changing environment that requires a value statement for the increasing cost of a college education for an ever-shrinking college-aged demographic. Faced with these responsibilities, administrators readily embrace faculty created and managed frameworks that satisfy both the demands of students and the business community. Student consulting projects yield advanced learning opportunities and graduates who are more employable due to their leadership skills.

\section{Currency in Promotion}

Storytelling is a critical component of the student recruitment process. Research suggests that consumers are more than 3 times more likely to trust information coming from a consumer than from the brand itself (Packard, 2019). With that, college and universities are handing over social media posts with endeavors like "takeover Tuesday," engaging students in texting campaigns with prospective students, and getting students even more involved in the recruitment process. While this is effective, today's students likewise want to picture themselves as part of the "story." They want a place to belong, and ways to see a successful, meaningful path for them at the university. As we know from research, Gen Z likes to feel involved and to have purpose (Perna, 2019). Having students who are currently engaged in consulting projects document their experiences via social media (with client permissions on file) can be an effective way to show prospective students how they can have real impact on the community through a program. Not to mention, students gain transferable skills that make them more employable, and improve their lifetime earnings potential - the ROI information parents want to see. Research shows that enlightened self-interest is a critical component of doing good as good marketing (Peake \& Eddleston, 2021). Prospective students must know what is happening within the program in order to integrate that information into their decision-making framework for college and major selection. Avid promotion of the benefits of students consulting projects can be an important component of promoting vibrant, meaningful messaging to current and prospective students. And, if the college or department is unsure of how to do this, consider engaging a student consulting team to help propose implementable and actionable solutions.

\section{Currency in Filling Achievement Gaps}

WKU, like many regional comprehensive universities, enrolls a healthy percentage of first-generation students. These students are the first in their family to attend college 
and compose a cohort that requires special attention. Not only do first generation students face unique challenges while attending college, they also face many hurdles prior to enrollment. Institutions such as WKU, which recognize these hurdles, are better prepared to provide students with the support and guidance they need. According to the National Education Longitudinal Survey (NELS) survey (Choy, 2021) students who have parents that do not hold college degrees are likely to have lower educational expectations and be academically less prepared. While there are several factors that contribute to college enrollment such as family income, educational expectations, academic preparation, parental involvement and peer influence, the biggest contributing factor is whether or not one parent holds a bachelor's degree. So, while first generation students lack this major influencer, they also receive less assistance from their parents when applying to college and rely more heavily on help from their school.

Awareness of such factors inspired WKU's strategic plan by establishing steps that help students become more academically prepared and strengthening relationships with high schools in the service region. The individualized Personal and Professional Development plan as well as the Comprehensive Advising Plan were put into place to assist all first- and second-year students, and most readily supports first generation students. WKU specifically seeks to lead efforts in partnering with $\mathrm{K}-12$ educational institutions to create both a better-constructed path to college as well as a smoother transition to university life. Many universities are implementing similar campus support programs. The question then becomes how can we support these students in the classroom and keep them engaged? Student consulting projects may be a key solution to integrating "belonging" and "meaning" into the curriculum throughout their college career.

Recently scholars have conducted research to better understand first-generation college students (FGCS) and more importantly their unique challenges which include perceived barriers and career outcome expectations. Ma and Shea (2021) found that a sense of coherence, a frame of mind related to how one experiences their environment as predictable and consistent on a daily basis, is a significant factor in how students manage difficulties that in turn lead to positive academic and career outcomes. In addition, sense of coherence mediated the relationship between perceived barriers and career outcome expectations whereas campus connectedness moderated the relationship. Campus connectedness denotes the degree to which students feel a sense of belonging and closeness to other students. The reason such results are of particular interest to our work is that student led consulting projects can provide a true sense of meaning to students' class work. The ability to analyze the problems of a business, along with their team, and recommend real solutions to solve issues is a highly tangible and meaningful experience that also fosters belonging.

While the above research offers significant insight, another study adds other important pieces of information to help solve the puzzle of how to help the "new student" entering college today succeed. Falk and Blaylock (2010) write that the traditional, 18 to 22 year-old residential stu- dent is on the decline. They define the "new student" as more non-traditional, in terms of both age and educational expectations, and also include FGCS in this cohort. One finding coincides with the above previous research in that this "new student" type may not necessarily look for more campus activities to feel connected, but rather seek highly career focused curricula and service learning experiences. Again, student led consulting projects help meet the needs of these students by offering interaction with businesses that lead to connections to real, potential employers and provide an opportunity to make a meaningful contribution in the business community. Falk and Blaylock (2021) also point to how this segment finds information about potential colleges. Unsurprisingly, the university's website is the first stop and perhaps the only stop that many of these potential students make in their search. The ability to easily promote the success of student-led consulting projects on a university website and/or social media has real appeal and is both readily understandable and related to meaningful experiences and career-focused curriculum.

\section{Opportunities Moving Forward}

We have explored how to foster currency via student consulting projects. Now, we address three key considerations for the future in structuring student consulting projects.

\section{Documenting Value in the Digital Age}

Research demonstrates that student consulting projects add to the value proposition of an applied business education. They help sell the story for programs, and allow discussion with parents related to return on investment for their child's education. As AACSB Standard 9 gains traction, colleges of business across the globe must seek out ways to measure and showcase societal impact. Student consulting projects tie strategy, applied mission, and Standard 9 objectives together in such a way that colleges of business can create concrete measurement of impact, along with crafting stories of the student (and community) experience. Further, such projects allow for intensive follow-up to continue to assess impact. Faculty and administrators can generate multi-stakeholder views that include the client and students during the project and the client and recent alumni one to two years post project. Employer surveys also allow for assessment of recent graduates to determine if students with consulting experiences, on average, perform better in their first job than those without such experiences.

Universities with an applied focus, tend to stress the importance of critical thinking, communication, and other transferable skills that enhance career preparation for students. As such, when offered as a capstone experience, student consulting projects create opportunities for students to share experiences from those projects in an interview setting. Multiple students have shared each year that their employer had questions about their experiences with student consulting and were impressed with what they had to share about the experience. These projects absolutely give students important, recognizable skills in applying their areas of expertise; however, they also help groom students as better listeners, more careful communicators, and yield understanding that most good work takes several iterations to 
be complete. Further, students learn about constraints in context, and how to frame solutions in ways that are palatable to a business owner and within his/her value system. Such skills are critical as students enter their first jobs and look to make impact. Having students speak to those experiences in testimonials as young alumni is good marketing.

Student consulting projects obviously yield positive impacts for students and community businesses. However, they also give programs the opportunity to curate stories, showcasing the strengths of their program. These projects, if carefully documented, provide valuable data to share in accreditation reports and strategic plan implementation updates. They can likewise showcase how a mission to provide students relevant and timely business (or other) education translates into practice. Further, in this area, Deans and Department Chairs within colleges of business are under increasing pressure to network in the business community in attempts to fundraise. Student consulting projects yield additional community ties and reciprocity. Positive experiences can lead to gifts from the business community and parents who are impressed with the efforts of the college to provide students an applied education, among others.

Although the Covid-19 pandemic initially brought challenges to student consulting projects, there are opportunities for growth that have arisen from the rapid adoption of videoconferencing technology. While it is preferable that students work with business owners in the university community, the now prevalence of video conferencing makes connecting teams to business owners easier than ever. For obvious reasons, it is valuable for students to conduct a site visit to understand the context and operations of the client's business, but additional meetings can be held with videoconferencing tools, yielding more convenience for both the business owner and student teams. When removing travel time, additional meeting opportunities are often available, making the entire process more fluid and flexible.

\section{The Value Proposition of Student Consulting Projects}

Researchers argue that alone, the average university level education does not make students employable or prepared to meet the challenges or opportunities facing them upon graduation (Pardo-Garcia \& Barac, 2020). Since the late 1990's, employability has become a key performance indicator of the efficacy of university education (Lowden et al., 2011). This is growing ever more critical in the United States as attitudes towards higher education have recently shifted. For example, a 2019 Gallup poll of 2,000 American Adults (Hess, 2019) found that only $51 \%$ indicated that they see college as "very important," compared to 70\% in 2013. This is a rather dramatic swing in attitudes and somewhat alarming given the biggest age group responsible for this change came from 18 to 29-year olds. In 2013, 74\% of 18 to 29-year olds saw college as "very important.” In 2019, that figure was down to $41 \%$. Both the aforementioned research on Gen Z and more recent work (Pardo-Garcia \& Barac, 2020) suggest that the value attached to skills over knowledge is increasing, since transferable skills create trainable, lifelong learners (Grotkowska et al., 2015). Student consult- ing projects yield exactly these experiences and transferable skills that both employers and researchers agree students so desperately need (Audet \& Marcotte, 2017). Additionally, these projects address the call from scholars, accrediting bodies, and practitioners alike for a renewed focus on social impact (Rosenberg, 2021) and "making meaning."

As part of this "call" to restructure the undergraduate educational experience, experts suggest that a more multidisciplinary approach to learning is key. While student consulting projects have a long history in entrepreneurship and management curricula (Canziana \& Tullar, 2017) applied projects of similar nature are often available in myriad programs, from fashion merchandising to engineering to tourism to medicine to music. Research supports that students engaged with industry problems and contacts during their coursework often encounter more success post-graduation (Smith et al., 2009). If multidisciplinary approaches to education are an imperative and engagement with industry improves educational outcomes, student led consulting projects provide a critical means for bridging the divide and creating value for student employability and industry networking.

Programs, such as entrepreneurship, engineering, and the arts often converge to have students work in interdisciplinary teams for business and industry problems. Such projects teach students valuable skills, such as how to interface with other operational areas in order to provide comprehensive solutions to industry or business-specific problems. This requires students to synthesize soft skills and discipline specific knowledge, while working with others to provide viable business solutions across domains. Such capabilities improve employability and yield critical experiences for students to share and leverage as they move towards and through their careers.

\section{Student Consulting Projects for the Future}

As with any curricular method or experience, it is important to evaluate the structure and format for student consulting projects to ensure they are serving both student and client needs. In our experiences at WKU, we have seen a distinct shift in clients' needs and preferences. Early-on, clients typically wanted a longer, more detailed written report. Currently, our clients prefer value-added activities such as website updates, social media plans, feasibility analyses for new products, customer research, etc., with future plans for continuation or implementation of the activity or item the student team created. Clients no longer want $50+$ page reports. They want graphics, diagrams, videos and figures to guide them through the process of continuously deriving value from the students' work.

Recently, our students helped a local ice cream and agritourism business conduct an industry analysis for a processor facility addition, which would allow them to utilize milk produced by their herd in the ice cream sold at the restaurant. Further, it would allow them to sell milk at grocery stores in the region. Students conducted blind taste tests for the business and provided an industry analysis, complete with consumer research, which the client was able to utilize in a grant application for value-added producers. The grant was awarded and our students and the university were rec- 
ognized for their role in helping the client gather and write this information. The client had a very targeted ask, which we are finding to be more typical as we continue building client relationships. These targeted tasks often make great "bite-sized" projects for classes throughout a program, not simply a capstone format. If these client trends continue, more specialized projects will likely arise; creating more opportunity to integrate such projects throughout the curriculum.

Student consulting projects can vary substantially, depending on the course and client needs. Appendix 2 contains an example assignment for how these student-consulting projects can be implemented in a basic entrepreneurship course early in the major curriculum. This gives students across disciplines the opportunity to work together. Appendix 3 provides the example guidelines for a college of business capstone course which revolves entirely around a semester-long student consulting project. Although these projects are incredibly different in scale and scope, both tangibly and significantly benefit clients, students, and the community.

\section{Conclusion}

Student consulting projects are a time-tested pedagogical tool that can serve as a bridging mechanism for strategy, accreditation standards and university/college mission. These projects develop student connectedness, create meaningful experiences for a generation that values meaning, improve students' networks, and enhance employability all while benefitting the community and creating economic value beyond the university. This work shares a contextualization for the student consulting model, provides strategies for curating currency through these projects, and provides key insights for future development of the project structure itself.

Submitted: April 13, 2021 MST, Accepted: October 01, 2021

MST 


\section{REFERENCES}

Arnold, W. W. (2018). Strengthening college support services to improve student transitioning to careers. Journal of College Teaching \& Learning, 15(1), 5-26. $\underline{\text { ht }}$ tps://doi.org/10.19030/tlc.v15i1.10198

Audet, J., \& Marcotte, G. (2017). Business consulting projects: An experiential learning opportunity for students [Working Paper]. Université Laval. http://ww w.fsa.ulaval.ca/sirul/2017-013.pdf

Blagg, K., \& Blom, E. (2018). Evaluating the Return on Investment in Higher Education: An Assessment of Individual- and State-Level Returns. Urban Institute. $\mathrm{ht}$ tps://www.urban.org/sites/default/files/publication/9 9078/evaluating_the_return_on_investment_in_highe r_education.pdf

Cengage. (2019). The career readiness disconnect: Are students prepared for the workforce? 4 Myths debunked. http://embed.widencdn.net/pdf/plus/cengage/rnnusrz 9tm/are-students-prepared-for-workplace-myths-ebo ok-761250.pdf

Garrett, G. (2016). How business education will look in the future. https://www.linkedin.com/pulse/how-busines s-education-look-future-geoffrey-garre

Gillen-O'Neel, C. (2021). Sense of belonging and student engagement: A daily study of first-andcontinuing-generation college students. Research in Higher Education, 62(1), 45-71. https://doi.org/10.100 7/s11162-019-09570-y

Hart Research Associates. (2015). Falling Short? College Learning and Career Success. https://www.aacu.org/sit es/default/files/files/LEAP/2015employerstudentsurve y.pdf

Hess, A. J. (2019). College grades earn $80 \%$ more - but only $51 \%$ of Americans see college as very important. CNBC. https://www.cnbc.com/2019/12/19/only-51per cent-of-americans-see-college-as-important-despitebenefits.html

Kuh, G. D. (2008). High-impact educations practices: What they are, who has access to them, and why they matter. Association of American Colleges and Universities.
Nicolas, A. J. (2020). Preferred Learning Methods of Generation Z. Digital Commons at Salve Regina University. https://digitalcommons.salve.edu/cgi/view content.cgi?article $=1075$ \& context $=$ fac staff pub

Packard, J. (2019). Who is telling your story? Inside Higher Ed. https://www.insidehighered.com/blogs/cal l-action-marketing-and-communications-higher-edu cation/who-telling-your-story

Pardo-Garcia, C., \& Barac, M. (2020). Promoting employability in higher education: A case study on boosting entrepreneurship skills. Sustainability, 12(10), 4004-4027. https://doi.org/10.3390/su121040 $\underline{04}$

Parker, K., \& Igielnik, R. (2020). On the cusp of adulthood and facing an uncertain future: What we know about Gen $Z$ so far. Pew Research. https://www.pewresearc h.org/social-trends/2020/05/14/on-the-cusp-of-adult hood-and-facing-an-uncertain-future-what-we-kno w-about-gen-z-so-far-2/

Payscale. (2016). Leveling up: How to win in the skills economy. https://www.payscale.com/about/press-rele ases/payscale-and-future-workplace-release-2016-wo rkforce-skills-preparedness-report

Perna, M. (2019). Gen $Z$ wants to change the world - at your company. Forbes. https://www.forbes.com/sites/ markcperna/2019/12/10/gen-z-wants-to-change-theworld-at-your-company/?sh=10d539f93c56

Roos, J. (2014). The renaissance we need in business education. Harvard Business Review. https://hbr.org/2 014/07/the-renaissance-we-need-in-business-educati on

Rosenberg, B. (2021). It's time to rethink higher education: What if our goal was creating social impact, not preserving the status quo? The Chronicle of Higher Education. https://www.chronicle.com/articl e/its-time-to-rethink-higher-education 


\section{Appendix}

\begin{tabular}{|c|c|c|c|c|c|c|c|}
\hline ACTIVIT & LOG & & & & & & \\
\hline Please log $t$ & e total hours $d$ & edicated to th & SBI report un & er the app & ropriate & itles. Rou & and to \\
\hline the nearest & quarter hour an & d use the follo & ving number sy & tem: & & & \\
\hline 15 minutes & 25 & 30 minutes $=$ & & 45 minut & $s=75$ & 1 hour $=$ & 100 \\
\hline & & & & & & & \\
\hline $\begin{array}{c}\text { Date: } \\
\text { Week of }\end{array}$ & $\begin{array}{l}\text { Discussion } \\
\& \text { Analysis }\end{array}$ & $\begin{array}{c}\text { Client } \\
\text { Meeting \& } \\
\text { Travel }\end{array}$ & $\begin{array}{l}\text { Planning \& } \\
\text { Preparation }\end{array}$ & $\begin{array}{l}\text { Writing } \\
\& \\
\text { Editing }\end{array}$ & $\begin{array}{l}\text { Class } \\
\text { Time }\end{array}$ & Total & \\
\hline 22-Jan & & & & & & 0 & \\
\hline 29-Jan & & & & & & 0 & \\
\hline $5-\mathrm{Feb}$ & & & & & & 0 & \\
\hline $12-\mathrm{Feb}$ & & & & & & 0 & \\
\hline $19-\mathrm{Feb}$ & & & & & & 0 & \\
\hline $26-F e b$ & & & & & & 0 & \\
\hline 5-Mar & & & & & & 0 & \\
\hline 12-Mar & & & & & & 0 & \\
\hline 19-Mar & & & & & & 0 & \\
\hline 26-Mar & & & & & & 0 & \\
\hline 2-Apr & & & & & & 0 & \\
\hline 9-Apr & & & & & & 0 & \\
\hline 16-Apr & & & & & & 0 & \\
\hline 23-Apr & & & & & & 0 & \\
\hline 30-Apr & & & & & & 0 & \\
\hline Totals & 0 & 0 & 0 & 0 & 0 & 0 & \\
\hline
\end{tabular}

\section{Appendix 1 - Activity Log Example and Link}

Link to Google Sheet

\section{Appendix 2 - Smaller-Scale Consulting Project Guidelines}

\section{FEASIBILITY ANALYSIS PROJECT}

Whether you are working on a project proposal for your job or assessing a business opportunity as an entrepreneur, a feasibility analysis is a critical first step for investigation. A feasibility analysis starts the process of understanding the industry along with current and future trends, how a product or service fits into that industry, and what basic costs and revenues can be expected for a few months. In looking at this for an existing business, a good first step is to make a few recommendations of how the business can align their strengths with the current industry opportunities to better position for the future.

\section{Outline for the Report}

1. Executive summary (1/2 page summarizing your work).

2. Business concept description.

3. Industry trends, opportunities, and threats.

4. Product or service strengths and weaknesses within the industry. How does this product or service "fit" or carve a niche?

5. Either financial feasibility (original idea) OR strategic recommendations (client)

\section{Guidelines for the Project/Report}

- An original idea is a business concept someone on your team is passionate about starting. It can range from a lawn mowing service to a high-tech start-up, but it must a real, viable, and legal business idea.

- Clients vetted by Dr. Peake will be introduced to the class. If you prefer to work with a client, I'll ask you to submit an "application" ranking your top 3 clients in order of preference and form teams from there. At least two teams will be assigned to each client.

- The report should be 5 pages or less. No cover page is required but team members' names must be on the report.

- Report must have references - more is better because it shows you have done your homework. References do not count towards the page limit.

- Large diagrams, tables or photos (1/2 page of more) should be located in an appendix. The appendix will not count towards the page limit.

- Report should be neat, eye-catching, well-written, full of high-quality content, and interesting. Create infographics and provide information in diagrams, bullets, etc. to supplement text. Make this something an investor or client would WANT to review.

\section{Steps for Completing the Feasibility Analysis}

1. Join a team. If you have an idea, great, find some folks to help you take that forward. If you do not have an idea or something you immediately want to inves- 
tigate, we have clients available to the class to work with. You can work on a REAL business and make an impact in the community.

a. I need to know your preference for a client or original idea by $\underline{1 / 24}$ at $11: 59 \mathrm{PM}$.

b. If you want to work on an original idea, join a team by $\underline{1 / 31}$ at $11: 59 \mathrm{PM}$.

c. If you want to work with a client, I'll assign you to a team based on preferences, strengths, area of study, etc. by 1/31 at 11:59 PM.

2. Start your personal research. If you have a client, set up a virtual meeting or phone call to learn about their business and what he/she wants to do. If you are working on an original idea, start setting up virtual meetings with "customers" you think are in your target market or other business owners in the industry to learn more about what they do.

3. Industry trends, opportunities, and threats. While you are talking to people, also learn about the industry. Find how the industry has performed over the past 5 years and the projections of performance and trends for the next 5 years. Outline the opportunities and threats in the industry. Find popular press articles, research industry reports on IBISWorld and other market research firms, etc. to support your claims. "I believe" is not enough to justify something. You need business reports, data, and interviews with people in the industry and who would be target customers to support your claims.

4. What are the strengths of the business concept (yours or your client's) and the weaknesses of the business concept? How does that fit into the industry to carve a niche or create a profitable opportunity? Who is the target market? How do industry trends align with strengths of the business to serve that target market in the future? Are there opportunities to expand the market?

5. If you are working on an original idea, use the information from the research you have gathered to start attempting to project some start-up and operating costs for 6 months. Work to justify your target market, sales reach and revenue projections for 6 months.

If you are working with $\boldsymbol{a}$ client, use the information from the research you have gathered to begin working to identify three strategic opportunities for them. These opportunities should be more than, "you need to set up a social media strategy." If the client needs to do that, create some example posts, create a social media calendar for them. Make sure you are adding value - not just sharing your opinion.

6. Start putting the information into a report and revising that report throughout the rest of the semester. I will meet with teams periodically via Zoom during Thursday class time to check in on progress, give guidance, and help you navigate the feasibility analysis process.

\section{Questions You Might Have}

How is a project like this helpful to me?

As a student, you are building a portfolio of work for your career. You are showing future employers, bankers, or investors that you are well-prepared, trainable, and ready to work. Applied projects, like this one, help you compile a portfolio of work that you can share moving forward in a job interview or to lay the foundation for starting your own business. Some of the transferable skills required as part of this project are:

- Conducting market research and discerning reliable information from unreliable information

- Listening to clients and/or customers to see pain points from their perspective(s)

- Identifying opportunities and seeing threats in an industry

- Understanding how a product/service can fill a profitable niche within an industry, based on research and data

- Working in a team and having hard conversations if the need arises about performance

- Working with a client to help them find strategic solutions to their pain points

- Gaining basic knowledge of financials and levers that can be pulled to improve profitability based on that information

- Adding value for a client in a consulting-based project (and discussing the specific value you added which hopefully is aligned with your future goals)

Grading and Peer Evaluations

Grading. You will be graded on the following deliverables as part of the project.

- A written report per the guidelines provided on $\mathrm{Bb}$.

- Two mini team presentations to update Dr. Peake on your feasibility project progress.

- A final presentation to be shared with Dr. Peake, the class, and/or a client

Peer Evaluations. Each team will complete three peer evaluations while working on the report. Your final feasibility analysis write-up and presentation will be weighted based on the peer evaluations. Instructions and processes related to the peer evaluations are provided on $\mathrm{Bb}$.

Final Written Project Rubric Components (150 points)

Overall organization/clarity/grammar (10 points) Content quality and information display (15 points) Entrepreneurial Thinking (25 points) Thoroughness of analyses (20 points) Product or service concept description (15 points) Industry feasibility (20 points) Product/service feasibility (20 points) (25 points) Financial feasibility or strategic recommendations

Final Presentation Rubric Components

Professionalism (5 points) points) Preparedness, evidence of practice as a team (5 Content quality and information shared based on the written report (15 points) Intangibles $\rightarrow$ enthusiasm, great versus "just ok," 
evidence of team cohesiveness (5 points)

How Do you Determine Financial Feasibility (original ideas only)?

To fulfill this portion of the feasibility analysis, you need to examine the following:

- How much revenue can you expect for 6 months based on the market position, target market, and serviceable market?

- What are the total costs of start-up?

- What are the operating expenses for 6 months to run the business?

- How will you financially make this work? The team will need to assess how the business can actually meet the needs for start-up costs and operating expenses. If it appears you can never recover the costs with the concept as designed, then work to get more creative. Can the business start smaller and bootstrap? Can the business run on a part-time basis? Is there a way to partner with other businesses to get it off the ground?

What is a Strategic Recommendation (clients only)?

Really good consulting reports and feasibility analyses tell a story to the reader. Lenders and/or clients want to see how you got from "Point A" to "Point Z." You begin with the opportunities and threats in the industry. Then, you outline how the client business's strengths can help them take advantage of those opportunities with strategic recommendations.

Basically, you're helping clients with the following process:

- Learn about industry and client's business

- Identify pain points and opportunities to help the business

- Develop a plan and value-added for the business surrounding alleviating those pain points or taking advantage of opportunities.

For example, suppose you are working with a local craft brewery and online ordering and curbside pick-up of growlers is a trend in the industry (opportunity) projected to really take off over the next 2 -year period. Your client is located in a busy part of town, and one of its strengths is location. You could propose a strategic recommendation that they implement an online ordering system by walking them through how to do that, make suggestions of a website building software or site (or local business), outline basic costs, and then create mock-ups of what it might look like for them and their particular business.

What are Some Things that You Might Do as Part of the Strategic Recommendations?

Strategic recommendations comprise areas in which you might help with or walk the entrepreneur through with your analysis, such as...

- Marketing materials and recommendations

- Social media marketing plan

- Website and/or payment portal

- Setting up a legal entity

- Certification for a women/minority owned business
- Financial analysis or QuickBooks set-up

- COVID-19 safety measures adaptation

- Entry or expansion into a new product/service area or location

- Market survey or research for a new product/service line

\section{Additional Resources}

IBISWorld (A WKU-owned database) provides comprehensive industry research on most industries

SizeUpKentucky a one-stop shop to size up competition within the state of Kentucky (SizeUp Training)

Market Research Guide this is a helpful article from HubSpot on market research.

NAICS Code lookup it can be helpful to have the industry code to locate market research

$\underline{\text { SCORE }}$ a great resource with numerous reports and great examples of infographics and aesthetic reports

State of Small Business Report a report put out by Facebook

\section{U.S. Chamber of Commerce}

NFIB November 2020 Report this is a report about small business optimism conducted in November 2020

Also, look at national industry organizations for great reports and information.

Infographic Report Examples

Below are some examples of publicly available reports from reliable sources that are eye-catching and that use infographics:

2020 Report on Employer Firms: Small Business Credit Survey

$\underline{\text { Microsoft Trends for Small Businesses } 2018}$

\section{Appendix 3 - Consulting Course Guidelines Example}

\section{Consulting Project Guidelines and Requirements}

As a business student, you have many wonderful experiences and a pool of knowledge to draw from in your careers. This course will allow you the opportunity to synthesize and integrate the information across your business courses to undertake a small business consulting project. These are intensive, semester-long projects that require dedication, critical thinking, professionalism, and teamwork; however, this is a win-win project. You get real-world experience and class credit for completing the project, while the business owner gets an in-depth analysis of some key components of his/her business. We will also work to make the project as manageable as possible by providing timely progress reports and taking a project management approach to organizing completion of the consulting project.

The first step in this process is to submit your student information sheet, with project preference rankings by the end of class on 1/22.

I will assign your teams of $\underline{\mathbf{4} \text { to } \mathbf{5}}$ students, as well as the business each team will be working with at the beginning of class on $\mathbf{1 / 2 9}$. You will be expected to assign duties within the group during the $1 / 29$ class period and work to make contact with the client during the following week. 
In the sections to follow, you will find guidelines and requirements for the letter of engagement, project, outline, draft and final consulting documents, and draft and final presentations. Peer evaluations are due with the project outline, drafts, and final project. Please see the Peer Evaluation documents on Blackboard in order to conduct these evaluations appropriately. All individual grades related to the team project assignments outlined in this document are subject to peer evaluation.

\section{LETTER OF ENGAGEMENT (LOE)}

\section{0 points}

The letter of engagement serves as a contract between you and the client about the objectives, approach (scope), and deliverables for the project. The letter of engagement clearly identifies what the team will do, why the team will do this, and the point at which particular items will be completed. Remember, the LOE is a negotiable document. Please adhere to the following deadlines for the LOE.

- LOE draft due to the Bb on 2/17 by 11:59 PM

- Deliver Letter of Engagement to Client by $2 / 26$ (this may include revisions by the client)

- Return signed Final Letter of Engagement (upload scanned copy to $\mathrm{Bb}), \underline{3 / 3}$ by 11:59 PM

The LOE should be structured with the following sections, written as a professional memo to the client (see example on page 62 of text or in the Appendices of the example projects).

- Brief Greeting

- Background

- Project Objectives

- Approach

- Client Deliverables

- Scope/Responsibilities

- Project Budget (note that no expenses are expected)

- Project Schedule

- Agreement and signatures

\section{PROJECT OUTLINE}

\section{5 points}

The project outline should indicate each section that will be present in your final consulting document (in order), and will serve as your table of contents. By each section, please note the status of the section, who completed (or will complete) the section, and the deadline for doing so.

The Project Outline is due in hard copy form, along with a peer evaluation, $3 / 3$ by 11:59 PM. Please note that page numbers are not necessary at this time.

\section{SMALL BUSINESS INSTITUTE ${ }^{\circledR}$ DRAFT AND FINAL CONSULTING DOCUMENTS}

There are two drafts for your consulting document due during the course of the semester. The first draft (50 points) is due $\underline{3 / 21}$ by 4:00 PM , and the second draft (100 points) is due 4/9 by 4:00 PM. I will review your drafts and return them to you. Your team will be required to edit the document and incorporate requested changes, so your final copy may be as polished and professional as possible.

The FIRST DRAFT must present the following sections in full and content related to basic ideas for sections noted with an asterisk (*):

- Business Description/Company History

- Firm Analysis

- Industry Analysis

- SWOT Analysis

- Owner Objectives

- Problems/Concerns

- Strategic Business Recommendations*

Please format the first draft according to the guidelines below, so you have a more accurate picture of how the project is shaping up at each stage. Keep in mind that your draft will be graded on quality, including grammar and sentence structure.

The second draft and final consulting documents must follow these basic guidelines:

- Your draft must be complete and secured with a binder clip.

- You must submit two copies (one for me, one for the client) of your final, professionally bound consulting report

- The entire report may be no more than 100 pages allinclusive (each page, including title, appendices, etc. count toward the limit)

- 12-point font for report text

- 1-inchmargins

- Double-spaced (2.0) report text

- Each page must be numbered consecutively

The final consulting report (100 points) is due 4/30 at the beginning of class. Peer Evaluations and completed Activity Logs are due by $\underline{5 / 2}$ at the end of class.

The overall consulting document adhering to these guidelines is to be divided into the following 5 sections, along with an executive summary (no more than 2 pages). Keep in mind that cover page and appendices are in addition to these sections and should support the information in the sections described.

\section{History (approximately 10-15 pages in length)}

In this section, the objective of the student team is to analyze the history of the client, as well as conduct an industry analysis. It is imperative that the student team performs a comprehensive examination in order to uncover trends, issues, and other relevant information that will help you better identify the client's real problems. It is recommended that this section be divided into three parts: (1) Analysis of the Firm, (2) Analysis of the Industry, and (3) SWOT Analysis.

II. Statement of the Owner's Objectives (approximately 1-2 pages in length)

In this section, the student team will identify the owner's short-term and long-term objectives. The key here is to identify the objectives of the owner, not the objectives of the student team. If the client does not have objectives, this can be viewed as a potential problem. If the owner does not 
have objectives, it is the responsibility of the student team to help the owner establish good strong objectives (shortterm and long-term).

\section{Problems (approximately 1-2 pages in length)}

In this section, the student team will identify the client's true problems. The student team should work with the client to uncover the most critical problems facing that particular business. Be careful that you identify problems, NOT SYMPTOMS! Generally speaking, the student team will work on 2-4 problems during the semester (or sometimes one major problem). Most problems have many smaller parts that also need to be fixed.

\section{Recommendations (approximately 30-35+ pages in length)}

In this section, the student team will offer comprehensive recommendations to the clients. All recommendations are to be thorough and complete. For example, if the student team identifies that one of the client's problems is the lack of a marketing plan, the student team will actually create a marketing plan for the client. The real objective here is to provide the client with a report they can use to help them make better decisions that benefit their business. In addition to the explanation of the recommendations, all costs associated with each recommendation should be discussed as well as how to properly implement it to make it work. THIS SECTION IS THE HEART OF THE CONSULTING DOCUMENT!!

V. Conclusions and Comments (approximately 1 page in length)

In this section, the student team summarizes the recommendations and thanks the clients for providing this learning opportunity.

\section{FINAL PRESENTATION}

You will have 20 minutes to present your information to the client with no more than 15 PowerPoint slides, including the cover and conclusion slides. At least 3 members of the group must present to the client, although all members of the team must be present (in professional dress) and stand with the team during the presentation. The business owner(s) and key stakeholders for the Department and Gordon Ford College of Business will attend the final presentations, so your presentations should be well-rehearsed and entirely professional. You will have the opportunity to practice your presentations, with extensive and constructive feedback prior to giving your final presentation to the client and stakeholders.

The practice presentations (50 points) will be held 4 / $\underline{23}$ and 4/25 and should mirror exactly how you plan to make your final presentation. All students are required to attend the practice presentation session to provide feedback to the teams presenting. The final presentations to clients and stakeholders will be held $4 / 30$ and $5 / 2$.

The final presentation (100 points) should include the items outlined below. Keep in mind that the slide recommendations are simply guides and not hard-and fast rules, although they are intended to help you maintain focus on the most important aspects; however, the $\mathbf{1 5}$ slide overall limit will be strictly enforced.

- Introduction of Consulting Group and Business Owner (1 slide)

- Analysis of the Firm, Analysis of the Industry, and SWOT Analysis (3 slides)

- Owner's Objectives (1 slide)

- Problems (1 to 2 slides)

- Recommendations (4 to 5 slides)

- Conclusions (1 slide)

- Thank you and questions (1 slide) 